\title{
A PEDRA PINELA - MARCO DE COTO
}

\author{
por \\ ANTONIO RODRIGUEZ FRAIZ
}

"Na branca escuma do mar

e na auga trasparente

Relucente,

Parez que vas a nadar...

(X. M. Pintos)

Pode que o poeta precursor, Xoán Manuel Pintos, a ollara. Arestora xa non existe e si existe achase asulagada polas augas do mar que teiman rubir e as do Lérez que o seu sino é baixar, tenra e eterna sinfonía dende o agurgullar o pé da ermida de San Bieito, nos outos do Candán; héroica e forte nos derradeiros compases, baixo a Ponte da Barca, onde a percurada Pedra Pinela debe ou debéu existir ${ }^{\text {! }}$.

Fai uns trinta anos que o profesor Filgueira Valverde e Alfredo García Alen, segredario do Museo de Pontevedra, con centos de colaboradores tiñan a punto de rematar a Carta Magna da Arqueoloxía da provincia de Pontevedra. Nela sinálanse mais de un milleiro de localidades históricoarqueolóxicas e milleiros de ouxetos catalogados. Tarefa que puxo no intre á provincia pontevedresa no foco de todas as da Penínsua, arestora aumentada por Rodríguez Casal, A., de la Peña Santos, Roldan Hervas, Alain Tranoy e tantos mais...

${ }^{1}$ A. Rodríguez Fraiz, As Pontes do Lérez. Ponte da Barca.

"CUADERNOS DE ESTUDIOS GALLEGOS", Tomo XL, Fascículo 105, Santiago 1992. 
Se hoxe aparecese a Pedra Pinela os problemas entre os concellos de Pontevedra e Poio esmoreceríanse, xa que este outeiro foi dende os tempos medievais punto de referencia e Marco de Coto denantes das xurisdiccións episcopais reitoras da Vila pontevedresa e frades bieitos de Poio e Lérez; tamén termo de lindeiros parroquiáis de Sancti Petri de Campaniola, San Salvador e San Xoán de Poio, e dende 1820 das divisións adeministrativas entre os concellos devanditos ${ }^{2}$.

Queremos amosar tres documentos, non moi antergos pero importantes para o noso obxeto; porque o primeiro fai referencia a dous castros, un deles inda nos derradeiros do século XVI, con edificacións castrexas: ... casas vellas..., ademais de unha torre ou castelo que na misma data chamábase: ... torre de los antiguos...

O primeiro documento é: Concordado otorgado el 7 de Agosto de 1596, entre el Monasterio de San Juan de Poyo, representado por el Abad Fray Francisco de Corboda y el Bachiller Debesa, Rector de San Pedro de Campañóo. Polo que o noso ouxeto importa di: ...e pusieron un marco en medio del camino Rl. que va de la Aldea de Campañóo pa. San Juan de Poyo, Combarro e otras partes: e de allí al marco que. está en el Cañizo, junto a la tomada de Villanva.; e a luego de las tomadas de Villanva., hasta dar con el Castro Cas F.m. (sic) en donde estan muchas piedras; e de allí al Castro de Giestoso, al alto del e de allí va dar al Lugar del Bao, que trahe Benito de Villanva... ${ }^{3}$.

O segundo documento que amosamos, tamen moi importante para o coñecimento dos lindeiros das parroquias de Campañó e San Salvador de Poio Pequeno; polo intre das divisións dos concellos de Pontevedra ó que pertence a primeira e ó de Poio do que é parte moi importante a segunda; ademáis porque fala da finca da Caeira, propiedade que logo foi do Marqués de Riestra, hoxe Cidade Residencial. A meiados do século XVIII era unha carballeira pola que pasaba o camiño veciñal para o embarcadeiro da Barca da Mercé, logo utilizado polo camiño de ferro a Pontevedra e Vigo, co que a gran propiedade ficóu dividida en duas partes, na de arriba o Marqués enxergóu a vivenda e na Caeira de abaixo unha telleira que traballóu deica non fai moitos anos.

Di o documento, falando de uns carballos que se achaban: ...Arrimados

\footnotetext{
${ }^{2}$ X. Fortes Bouzón, Centenario del Puerto de Marín. 1886-1986.

${ }^{3}$ Vide Legajos. Ano 1956. Arq. Parroq. de Campañó.

"CUADERNOS DE ESTUDIOS GALLEGOS", Tomo XL, Fascículo 105, Santiago 1992.
} 


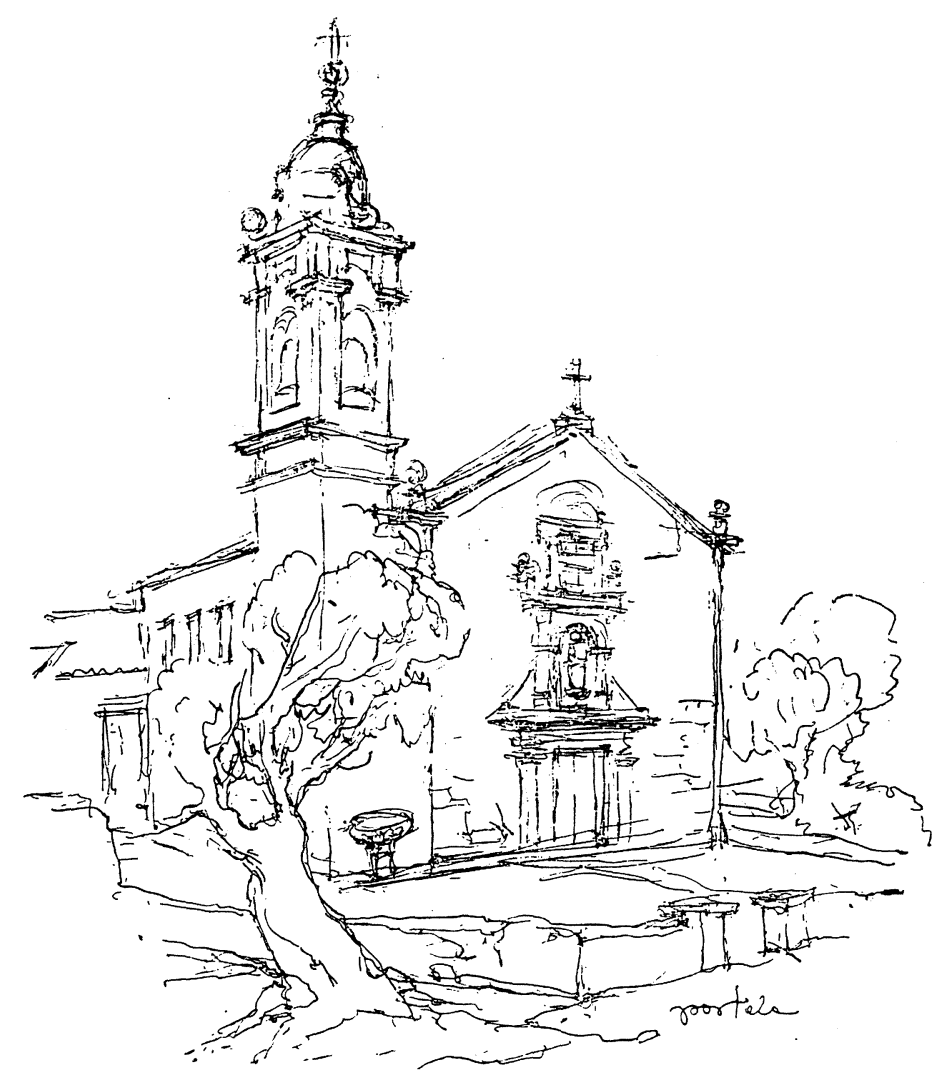

FACHADA DA EIREXA PARROQUIAL DE SAN PEDRO DE CAMPAÑÓ.
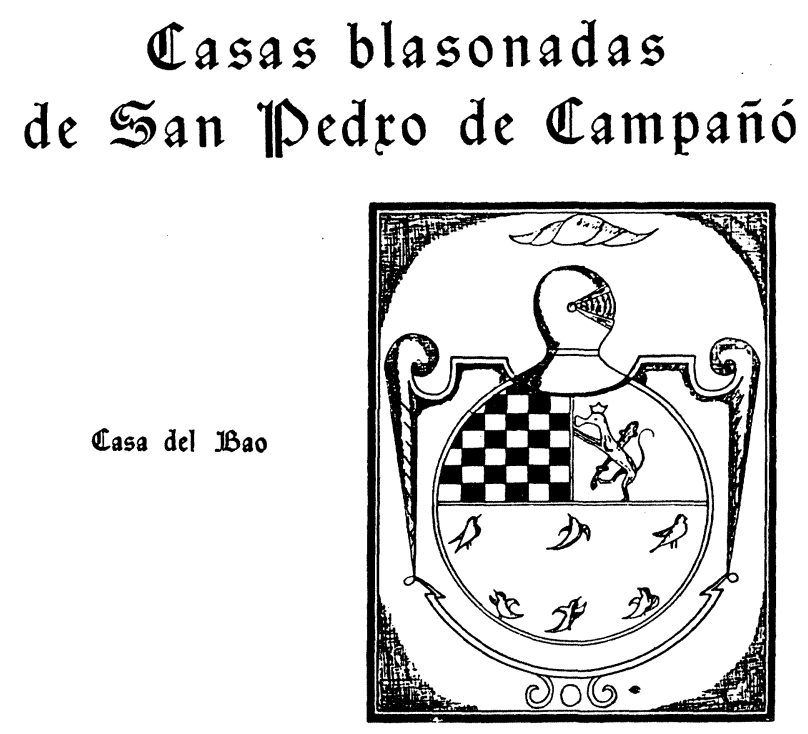
al camino a la fra. de Campañó ${ }^{4}$. Amosa ademais os nomes de unha das mais prestixiosas familias da vila pontevedresa, benfeitores das parroquias de Campañó e Santa Maria de Pontevedra cuios templos de unha e a outra debense, en boa parte, a munificencia da misma. $O$ de Camapañó a Don Roque Antonio Sanchez Moscoso Fernandez Barbeito y Quiroz e o seu sobriño don Manuel Xosé Sanchez Barbeito, os dous abades de Campañó dende o 1697 o 2 de Xaneiro do 1745 o primeiro e dende este ano ó 14 de xuño do 1781 o segundo. Familia con sepultura propia en San Bartolomé "O Vello" de Pontevedra e casa propia na Plaza da Ferreiria a chamada "Casa das Caras".

Documento de poder para vender feito na freguesia de San Vicenzo de Caamouco-Ares o 7 de Abril do 1751, diante o escribán Simon Sánchez de Andrade por don Nicolás Saayedra y Parga e sua muller, dona Francisca Xaviera Nóo y Luna, veciños de Caamóuco; dona Francisca Xaviera era filla de don Domingo de Nóo e dona Maria Ignacia de Luna, veciños de Pontevedra. Os bens que herda dona Francisca de seus pais contase a finca da Caeira, no intre toda en unha peza: ...sitos en la fra. de Poio pequeño con sus arboles de dar y na dar fruto, demarcados de sobre sí, y porción de robles pegado a ellos y a su circumbalación segun son mui bien conocidos $y$ de dominio de don Diego Luis Vermudez a quien paga renta pacttable anualmente...

Este don Diego era o señor da Casa Grande do Bao-Campañó-cuios principios parecen datar do século XIV. O que si costa é que dende o XVI aparece xunguida o Señoria de Gondar. Ostenta na fachada sur un escudo, labra evidentemente anterior a casa: partido e cortado, amosa o axedrexado na primeira partición dos Bermudez; na segunda óllase un león, posible relación cos Fernandez de Barbeito e Padrón, da vila de Pontevedra e Campañó, como xa se fixo costar; na terceira parte ollanse seis pombas que na Galiza eran patrimonio dos García ${ }^{5}$.

O poder, entre outros sitios, amosa bens de dona Xaviera en San Breixo de Barro, Briallos... y la mitad de treze Robles que están en un sitio solos en el campo qe. llaman del bao arrimados al Camino que pasa desde el embarcadero do bao, a la fra. de Campañó...

Dato este moi importante porque sinala o camiño divisorio dende o

\footnotetext{
${ }^{4}$ Arq. do Concello de Ares. Protocolo do ano 1751

${ }^{5}$ X. S. Crespo Pozo, Campaniola, Casa del Bao.
}

"CUADERNOS DE ESTUDIOS GALLEGOS", Tomo XL, Fascículo 105, Santiago 1992. 
embarcadeiro do Bao e Campañó, ficando polo intre a dereita de mismo as terras da freguesía de Poio Pequeno e a esquerda e dereita do río Lérez encetan as de San Pedro de Campañó; como as divisións civís seguiron ás da Eirexa tamen as dos concellos de Pontevedra e Poio, como millor costa no protocolo que amosamos seguidamente.

O 12 de xullo do 1763, o devandito Rector de Campañó don Manuel Xose Sanchez Barbeito en compaña do Vicecura don Miguel Rodríguez e Frai Xosé Bulló, Procurador do Mosteiro de Poio, fan un novo: recoñecimento: y revision de los marcos que dividen las dchas. fras. y las separan una de la otra... nos pusimos todos a la vista del Outeyro do Picón (no monte Castrobe). Van seguindo e anotando os lindeiros que sinala a Concordia do século XVI, engaden novos marcos e novas cruces, pasado o rueiro da Fragamoreira e xa nos termos do Montecelo di: ...De este dcho. marco antiguo do Cañizo en derechura al Outeiro do Castro qe. tiene muchas piedras y esta sito en monte comun,... y en donde los de Campañó ponen dos guardas pa. la monteria,... sin que pueda equibocarse con el Arcaje o Torre Vieja de Moreira, cuios vestigios de haver sido Torre de los antiguos, aun se le conocen y asi se llamaba pr. los años de 1584 ... y el otro señaló con una Cruz una Peña Redonda, sita en el monte comun sobre el camino que va del Monasterio para la Casa de dicho Rector ázia el Oriente; y en donde oy llaman Casas Vellas... De este dcho. Outeiro do Castro (al que oy llaman algs. el Outeiro da Tomba). Eiqui hoxe achase unha outa torre e departamentos da T.V.E. Sigue o interesante documento: ...y al que sigue el Outeyro do Corbo entre los que toman requento de la monteria los vezos. de la fra. de San Juan del Poyo; y los de la de Campañó.

Para o ouxeto de este estudo deica os lindeiros de Pontevedra e Poio e o mais importante. Sigue decindo: De este (Outeiro do Corbo) en derechura "Aguas Vertientes", cortando por el Outeyro da Tomba, que. es marco de Coto, y está sobre la Fuente da Tomba, qe. corre pa. la Casa do Bao; topando en la mesma Casa do Bao pr. la parte del Vendaval cuia Casa tambien es Marco de Coto; y queda toda ella pa. Campañó y cortando en derechura pr. el lugar de Bao, qe. antes fué de Benito Villanva. y oy deste es caveza Benito Paz; hasta dar en la "PIEDRA PINELA", qe. está en medio de la Ria de Pontevedra y la qe. juntamente es "Marco de Coto"; en donde se acaba esta demarcación... ${ }^{6}$.

\footnotetext{
${ }^{6}$ Vide Legajos. Arq. Parroquial de Campañó. Ano 1763.
} 
A cuestión pois é coñecer o punto onde se achaba o derradeiro: Marco do Coto a "PEDRA PINELA".

Os devanditos protocolos, dinnos con toda certeza que a tal pedra Marco de Coto, achabase no meio da Ria de Pontevedra; que a ela chegábase polo camiño do embarcadeiro da Barca da Mercé, lindeiro como se sabe da Campañó e San Sanvador de Poio; sobor do embarcaeiro o Marqués de Riestra nos derradeiros anos do século XIX, mandóu enxergar unha ponte de madeira, logo á de pedra, cemento e ferro, segun se acha no intre ${ }^{7}$.

Nos derradeiros meses do ano 1988, co gallo de unha nova e mais ampla estrada pola beira do Lérez cortaron a Ponte da Barca. O traballar nas cimentacións para os novos arcos de paso para a dita rua e rebaixar as terras para a estrada; a beiriña da Ponte e banda de Pontevedra a esquerda do rio, descubréuse un amplo outeiro de uns tres metros de outo sobor das augas, denantes de facer os entupidos da beira do Rio, a meiados do derradeiro século debeu acharse case que no meio das augas, como din os documentos, sobor de todo nas mareas outas.

¿Será esta longa pedra, arestora descuberta e que poidemos ollar dinamitada os poucos dias para dar paso comenente a pista de rodaxe para a ampla e nova rua de Beiramar pontevedresa a PEDRA PINELA?

Coidamos que é o mais probable. De ser esto asi teriamos o descuberto a tantas veces nomeada PEDRA PINELA e Marco de Coto, que divideu as terras episcopais pontevedresas, as mosteirais de Poio e Léreze as parroquiais de Campañó, Santa Maria de Pontevedra, San Salvador e San Xoán de Poio. Dende as liquidacións das xurisdiccións señoriáis polas Cortes de Cádiz ó xurdir os novos concellos, entre estes e efémero de Alba, formado polas parroquias de Campañó, Cerponzóns e Lérez no 1835 integrado no de Pontevedra tamén para éstes a PEDRA PINELA foi punto de referencia para encetar os lindeiros de Pontevedra e Poio.

O morno sol do outono quentóu por alguns dias a PEDRA PINELA para definitivamente desaparecer impiedosamente mordida polos aceirados dentes dos artefactos modernos.

${ }^{7}$ Ilustración Gallega y Asturiana. Tomo I. e Op. cit. Nro 1.

"CUADERNOS DE ESTUDIOS GALLEGOS", Tomo XL, Fascículo 105, Santiago 1992. 


\section{$5-\pi$ II I I -1596}

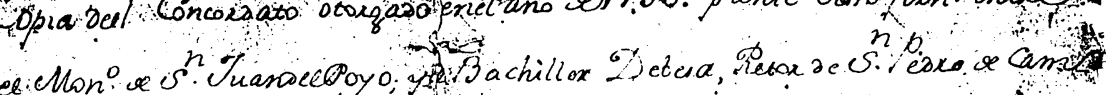

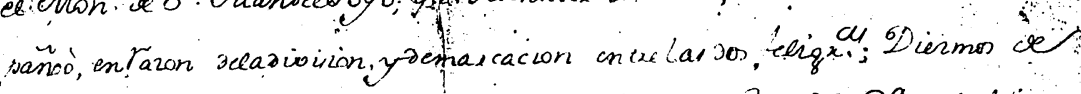

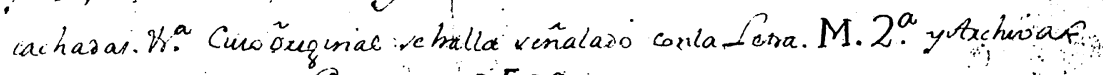

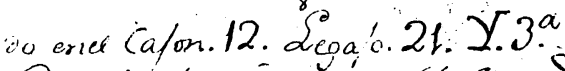

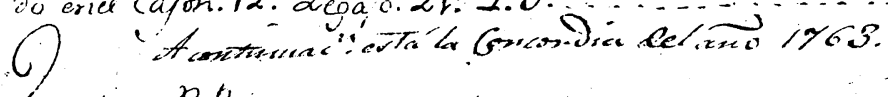

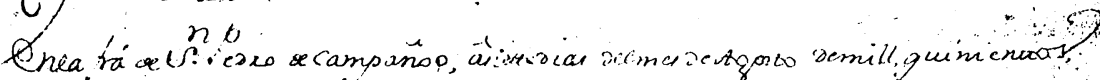

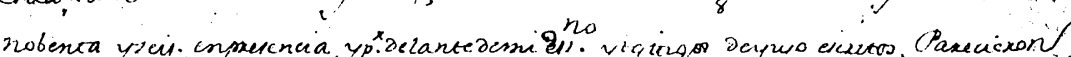

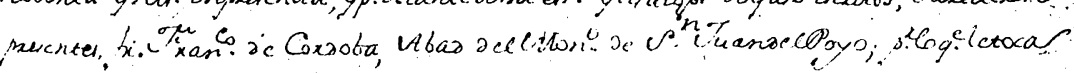

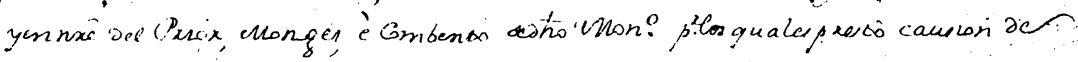

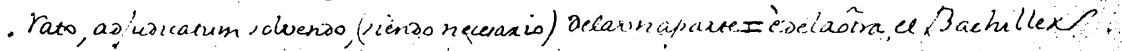

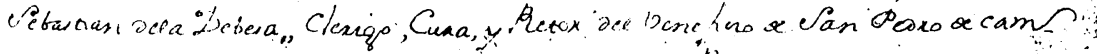

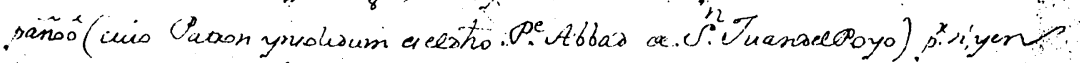

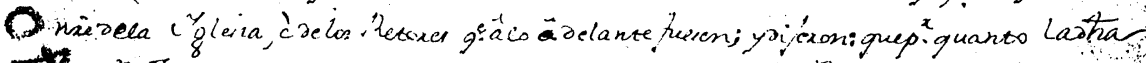

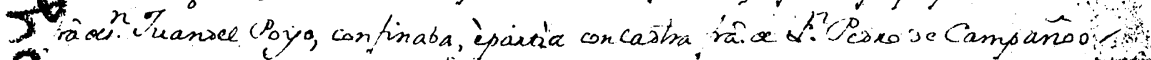

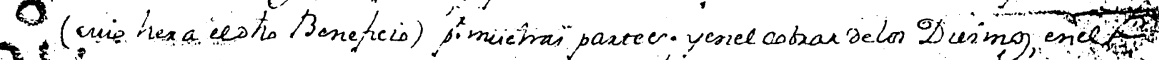

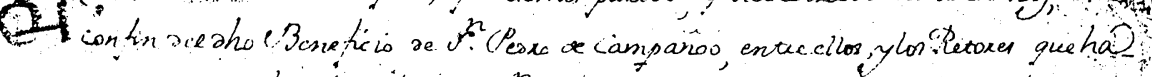

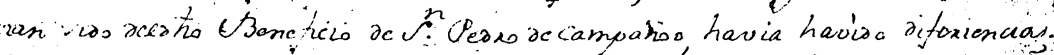

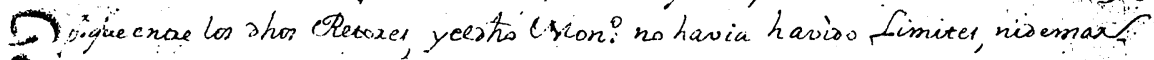

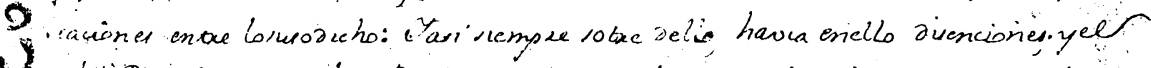

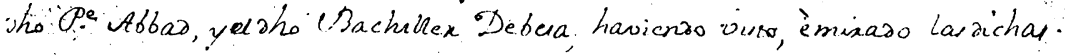

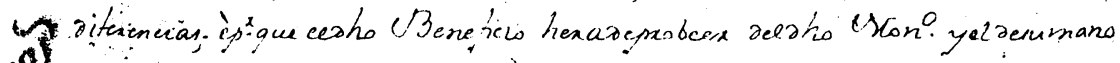

is

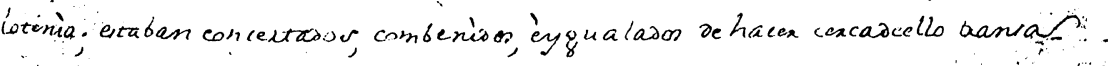

A

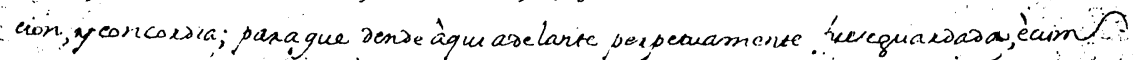

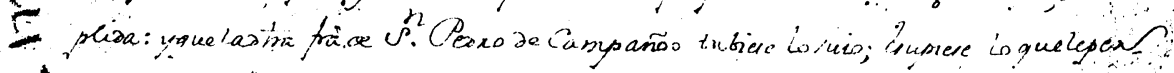

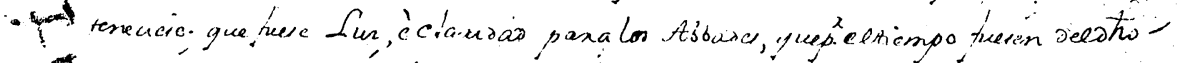

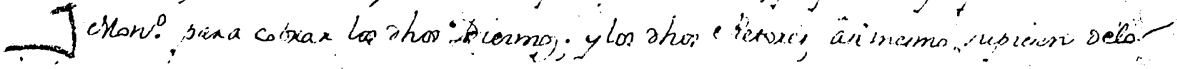

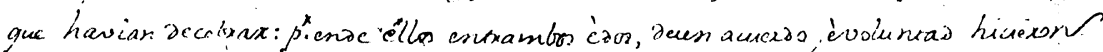

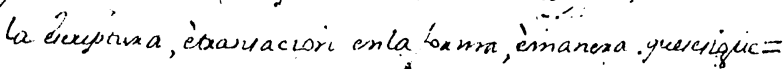

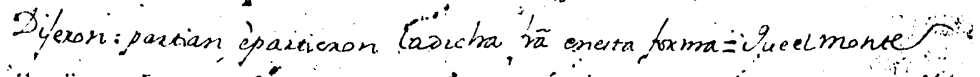

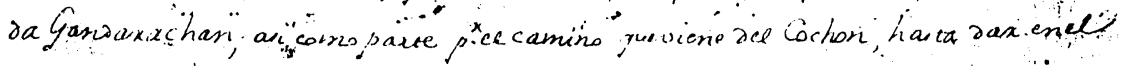




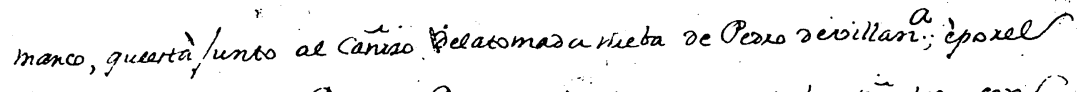

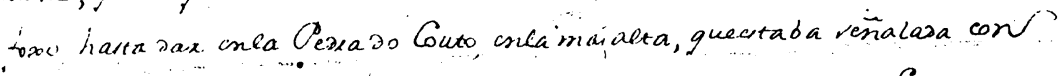

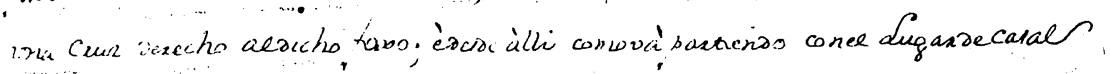

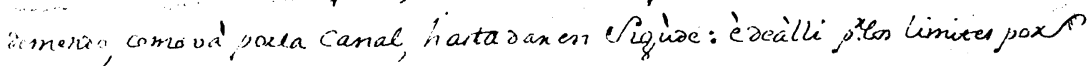

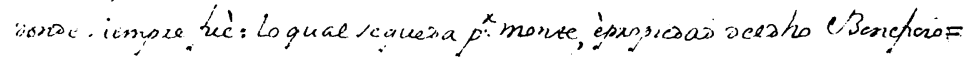

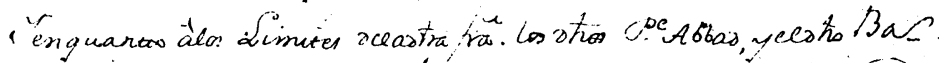

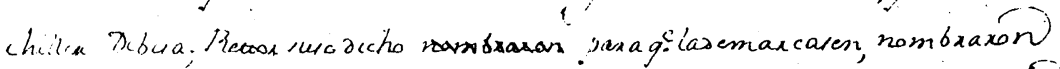

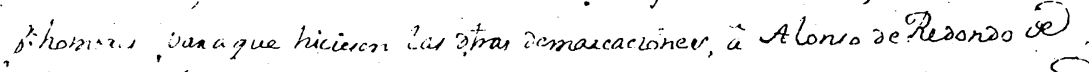

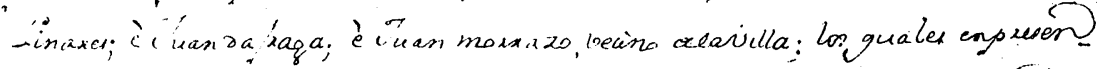

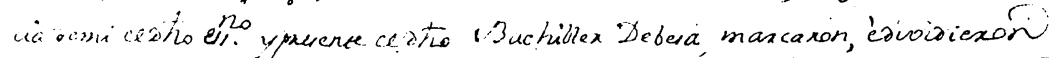

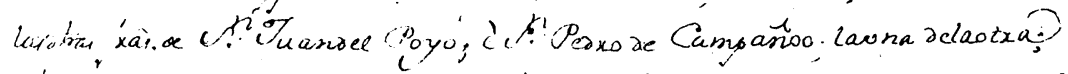

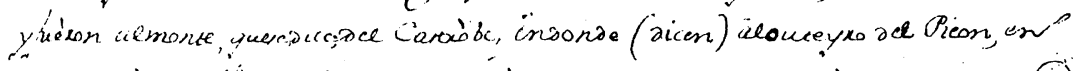

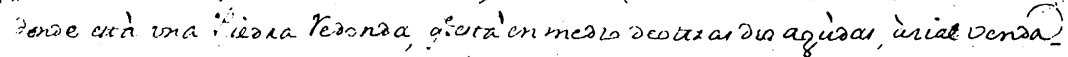

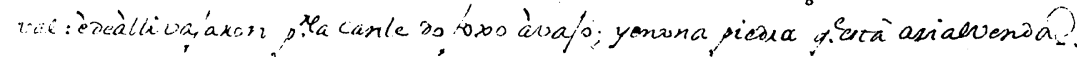

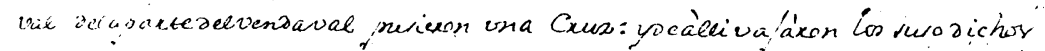

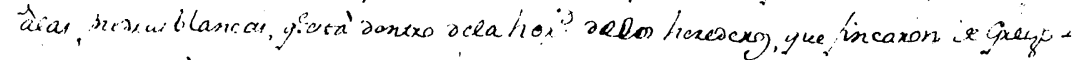

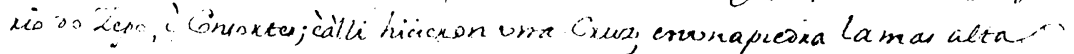

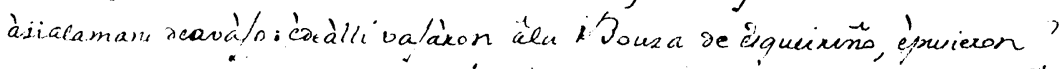

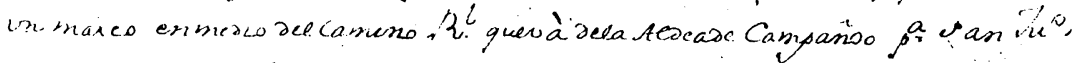

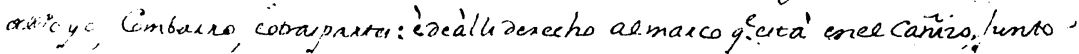

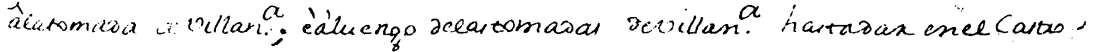

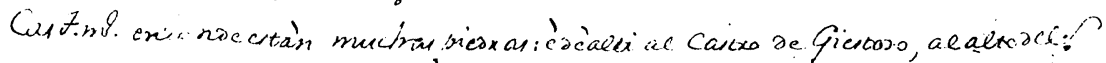

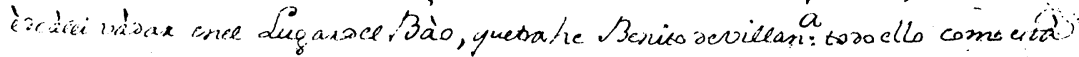

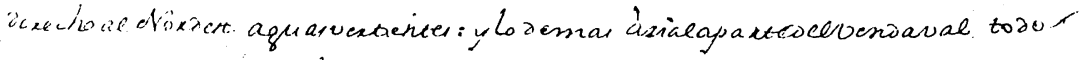

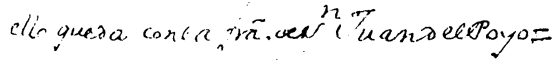

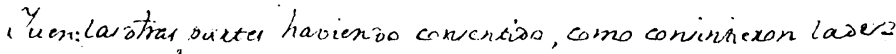

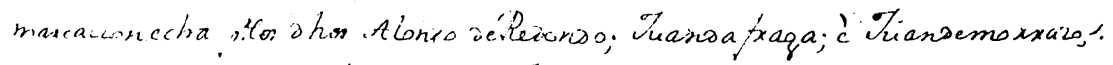

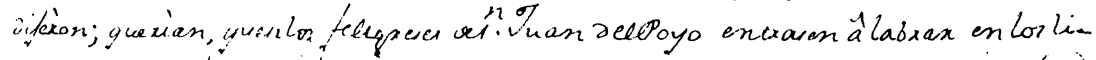

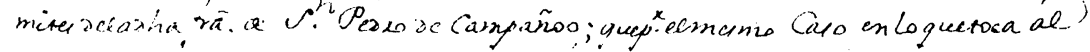

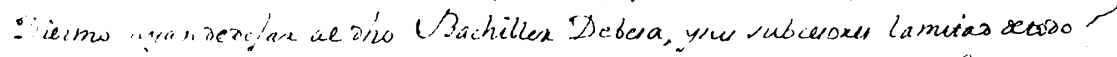

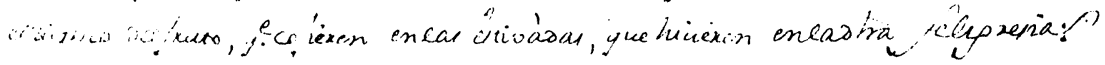




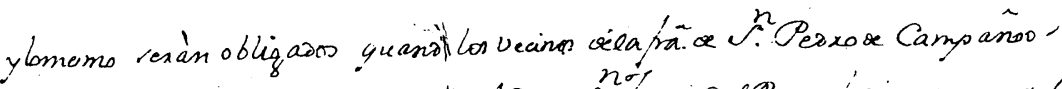

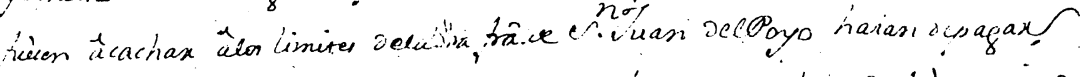

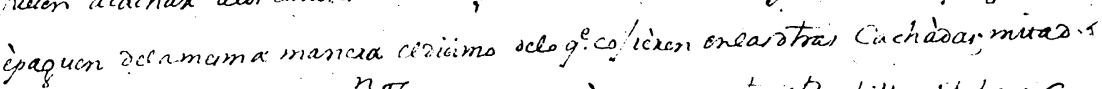

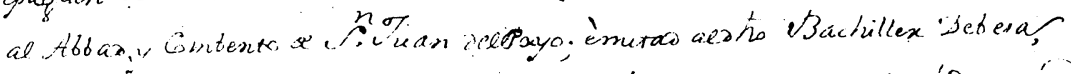

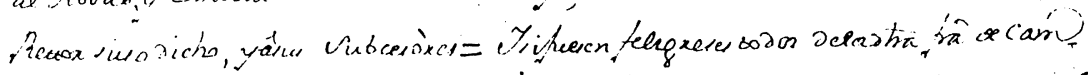

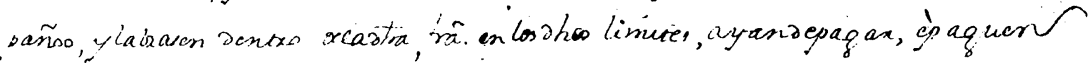

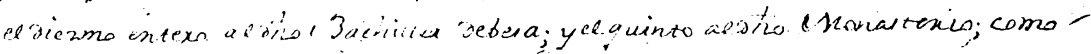

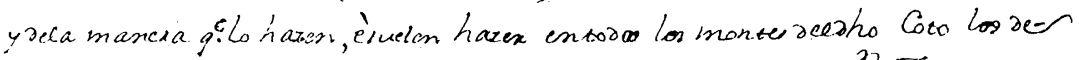

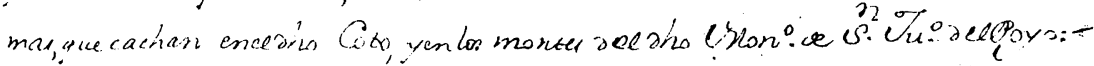

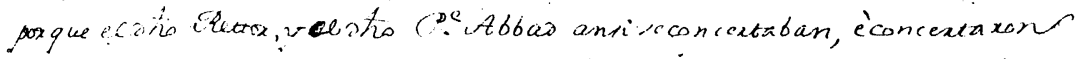

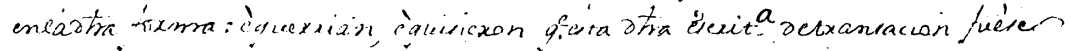

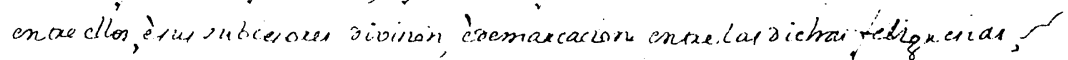

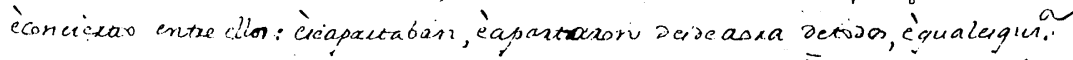

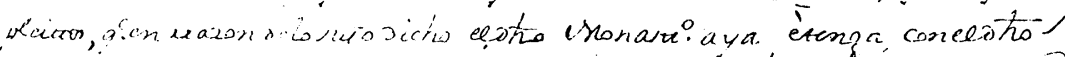

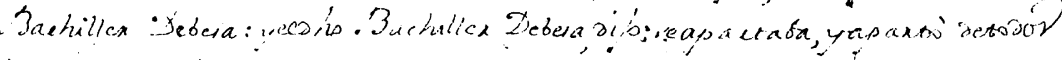

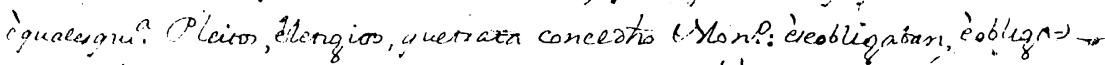

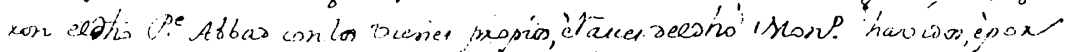

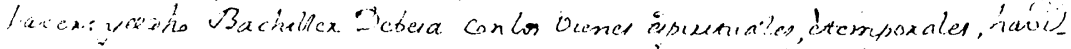

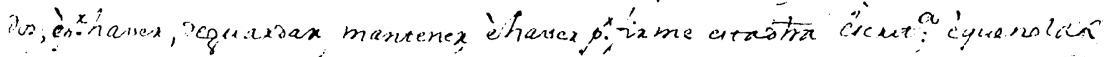

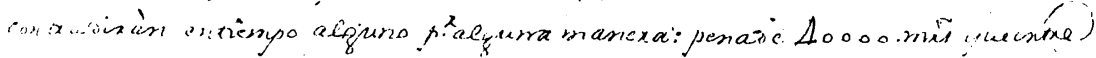

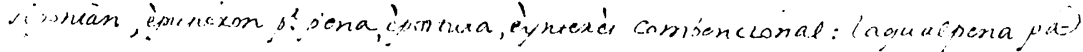

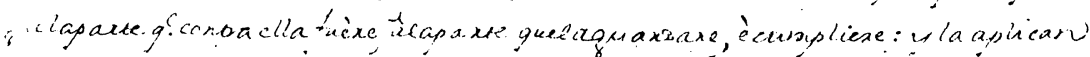

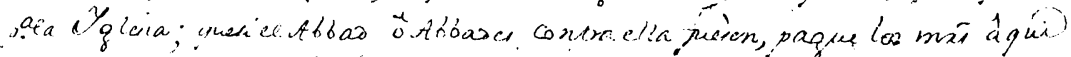

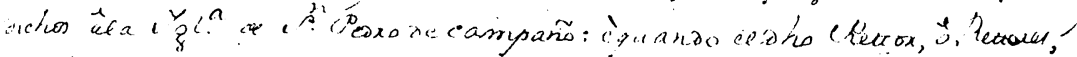

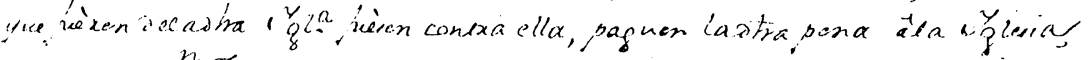

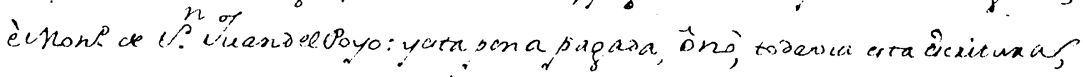

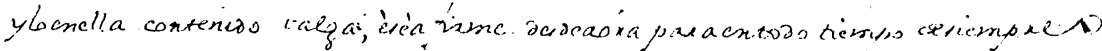

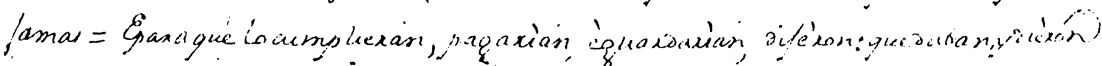

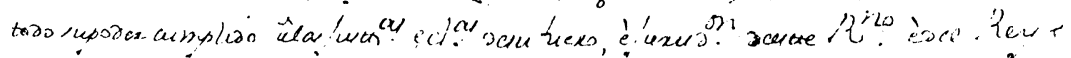

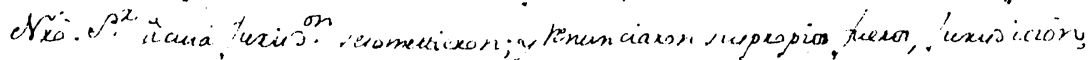

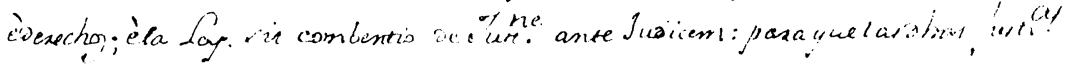




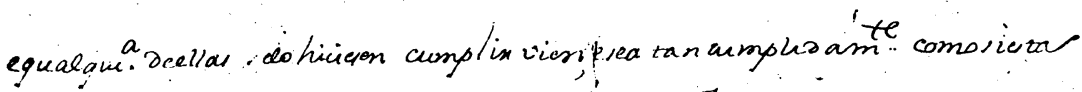

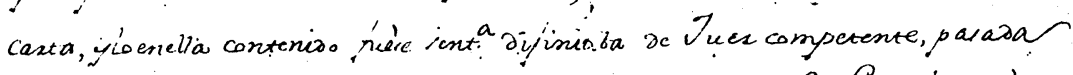

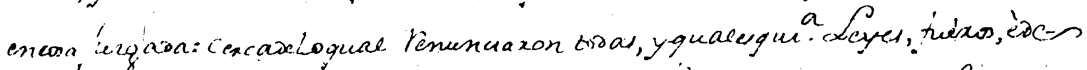

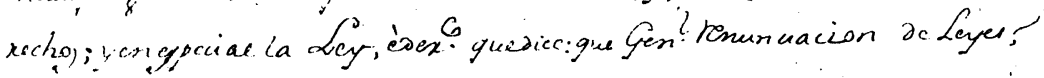

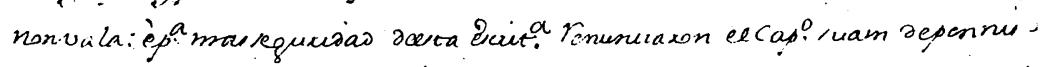

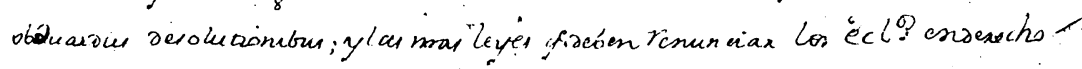

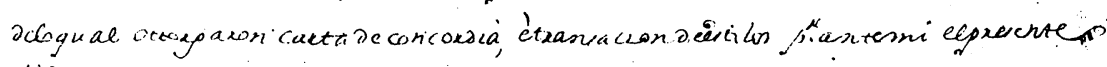

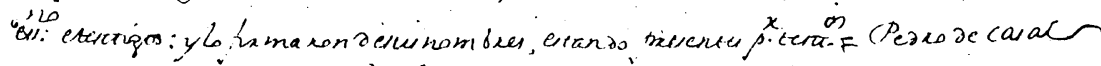

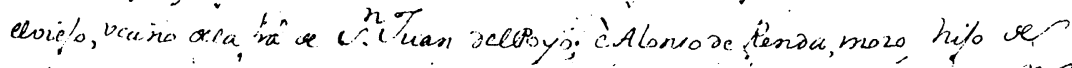

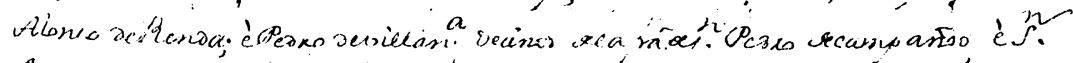

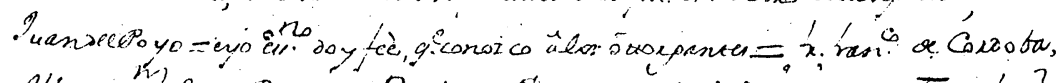

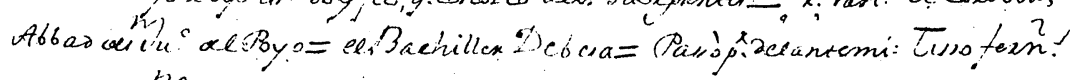

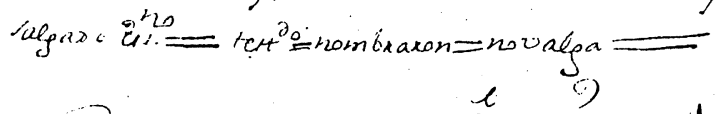

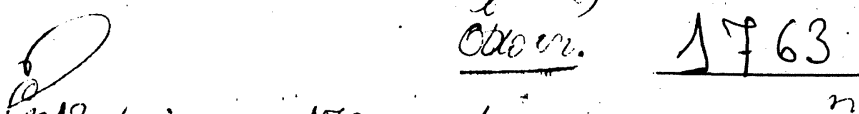

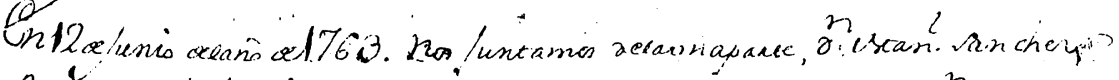

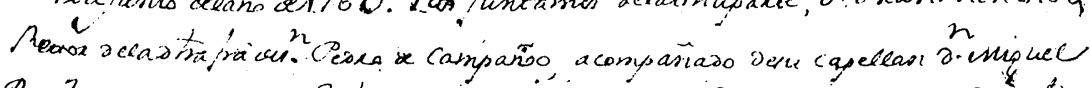

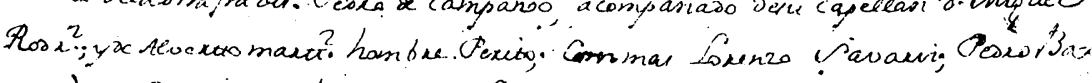

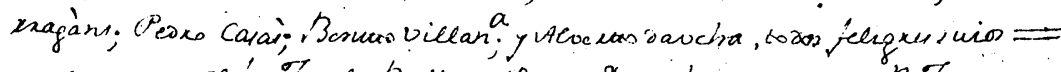

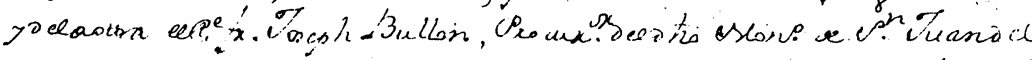

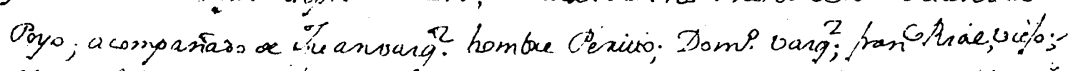

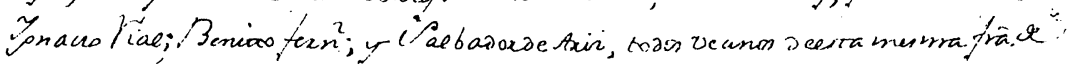

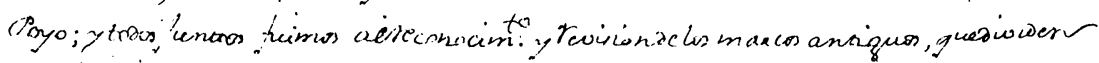

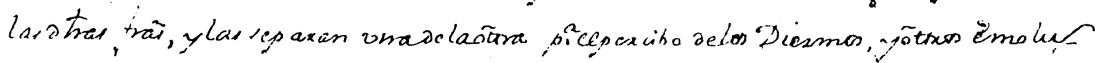

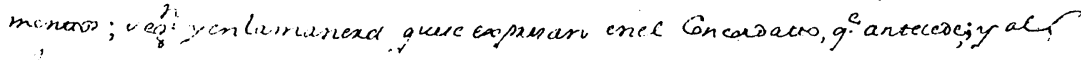

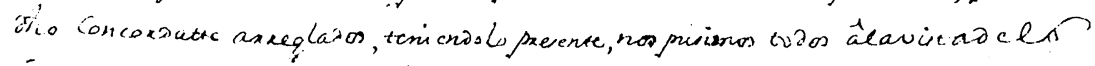

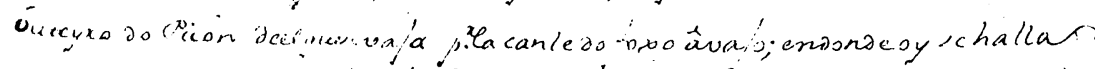

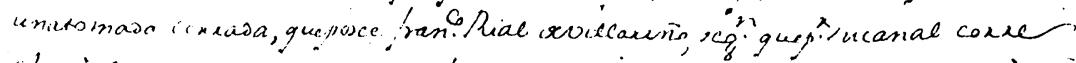

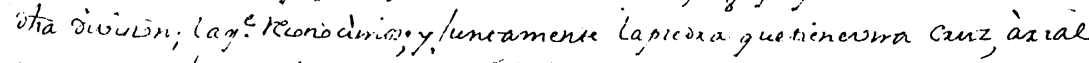

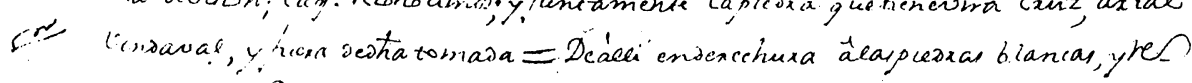

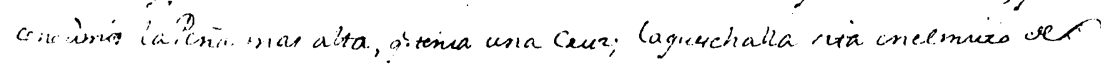




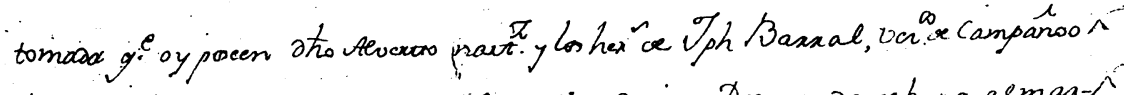

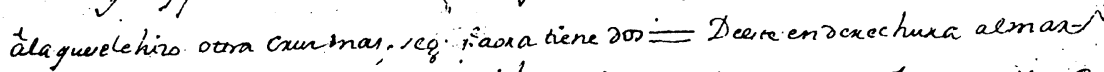

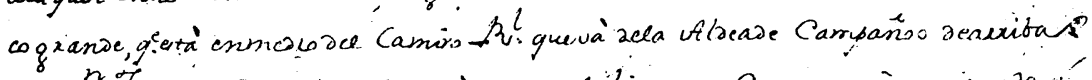

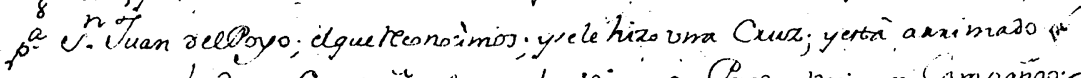

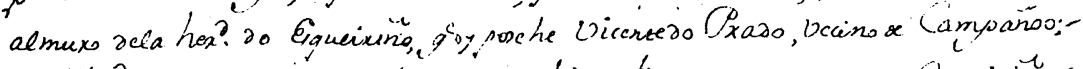

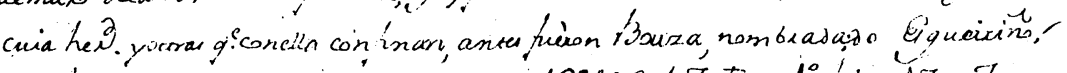

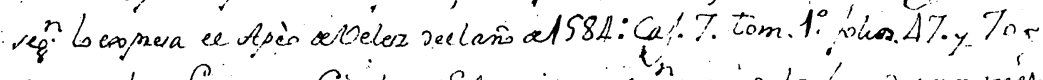

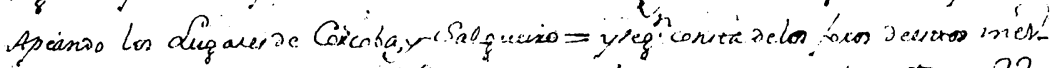

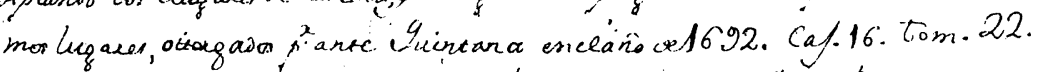

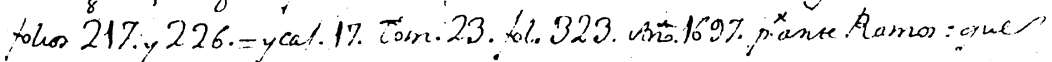

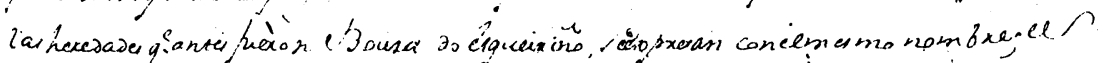

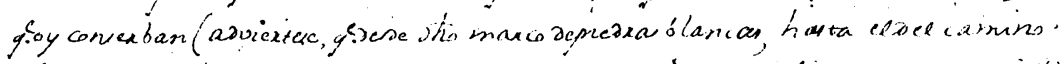

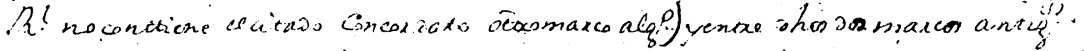

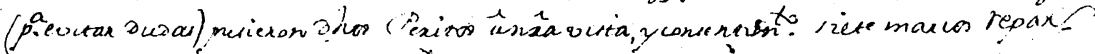

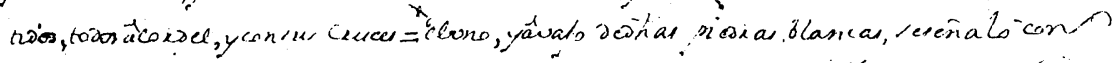

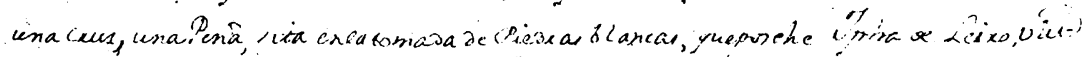

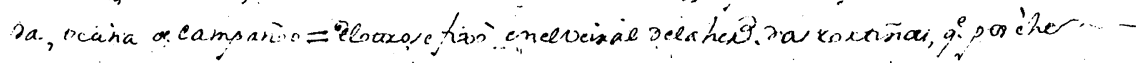

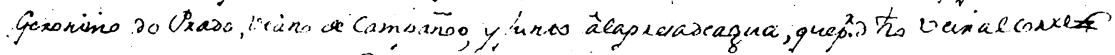

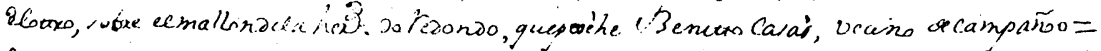

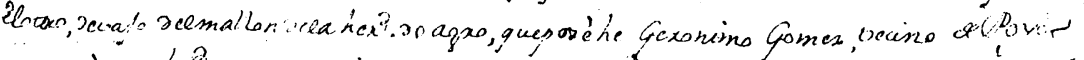

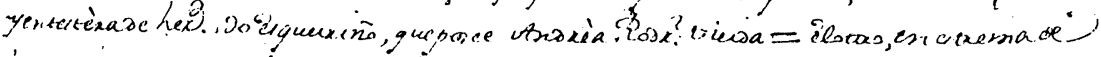

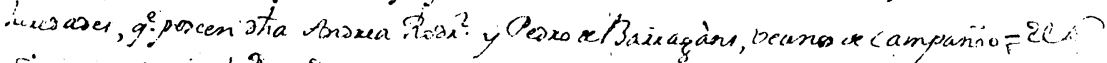

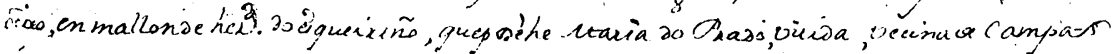

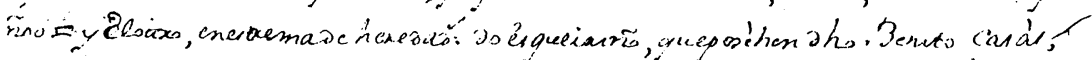

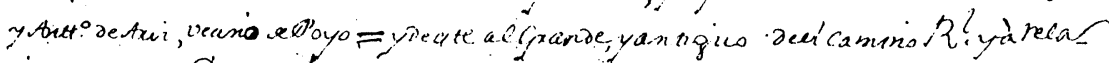

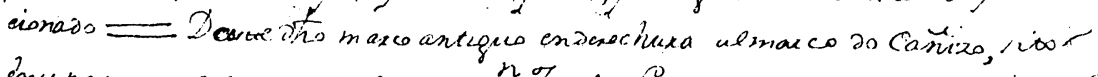

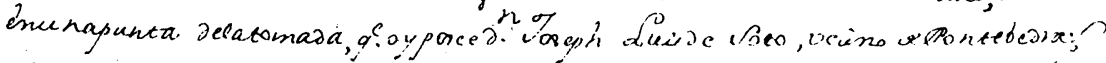

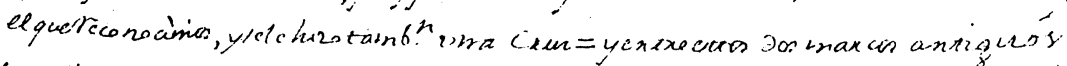

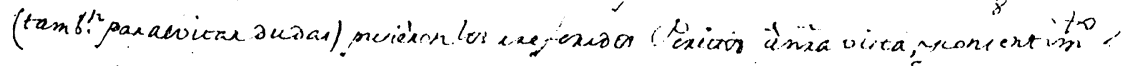

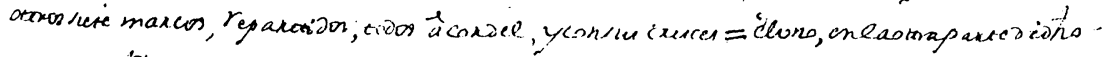

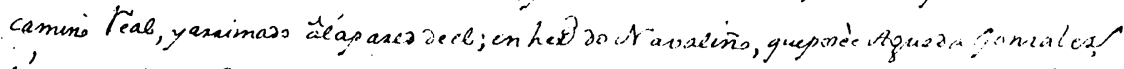

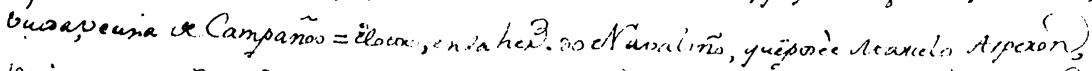

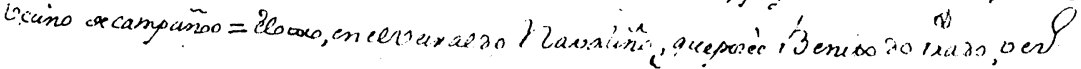




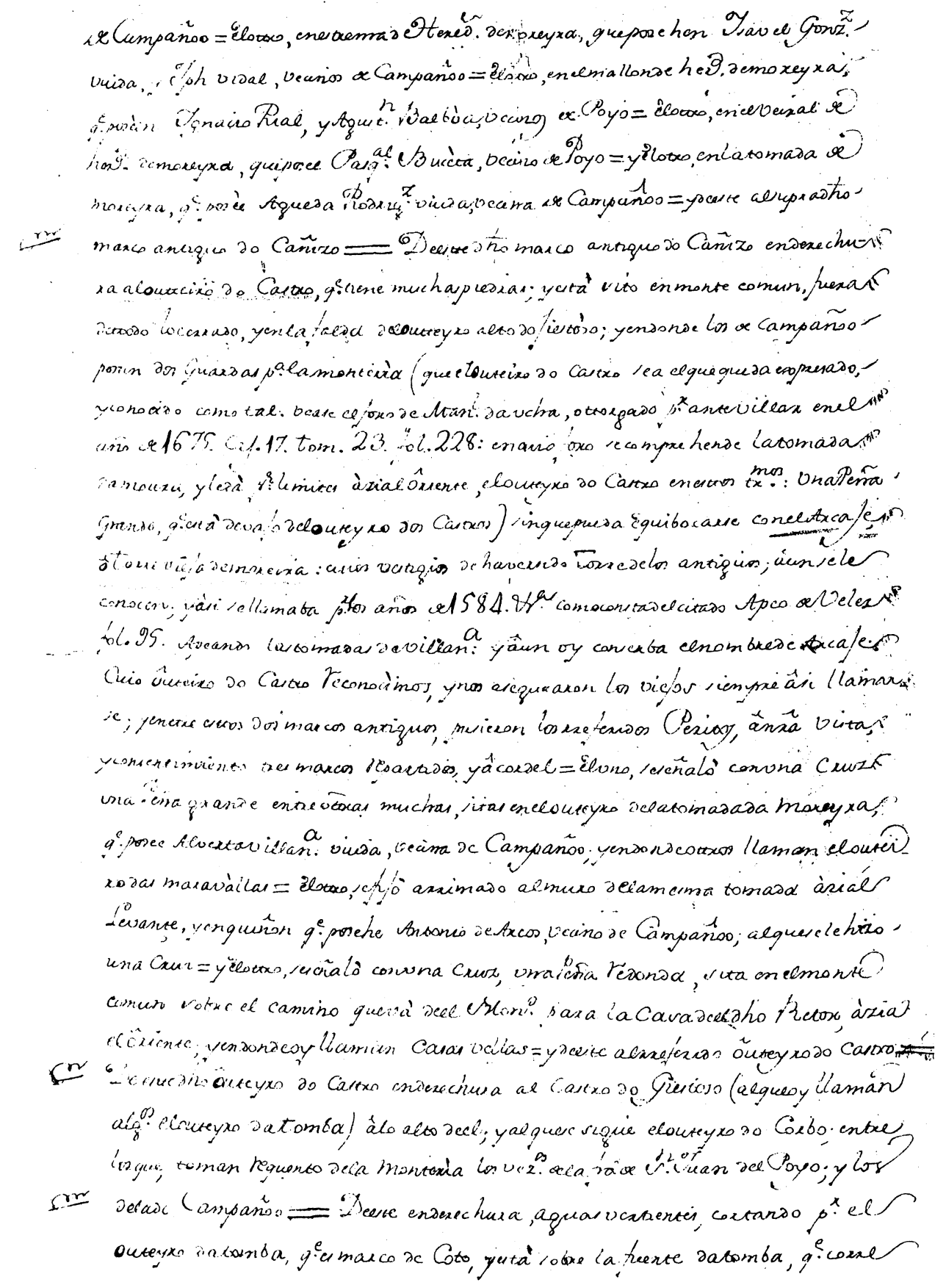




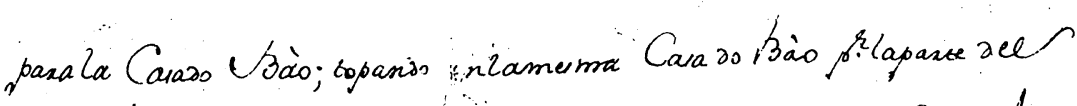

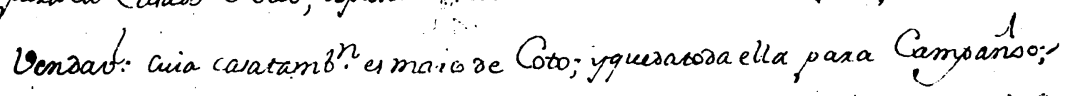

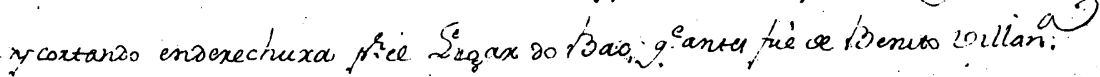

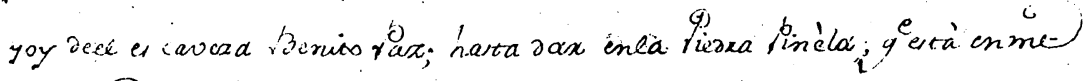

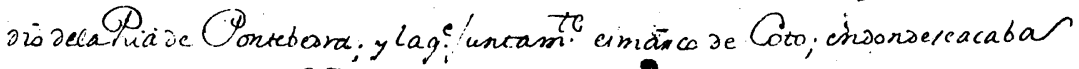

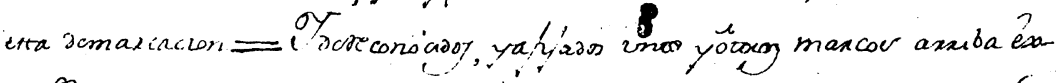

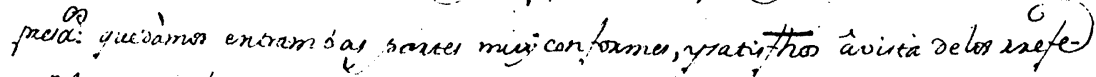

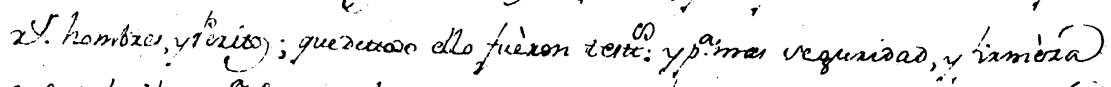

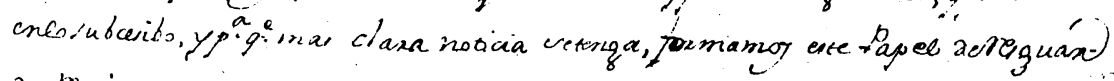

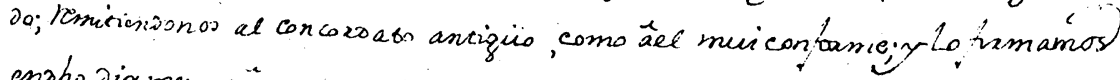
enoho jia, mes, yaño: vesupra v

fi: Benito A Lonio Abad de in Juan del Poyols

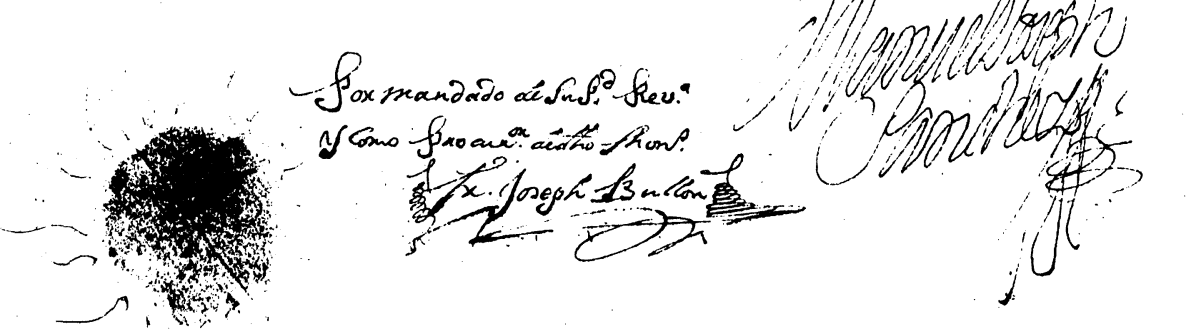




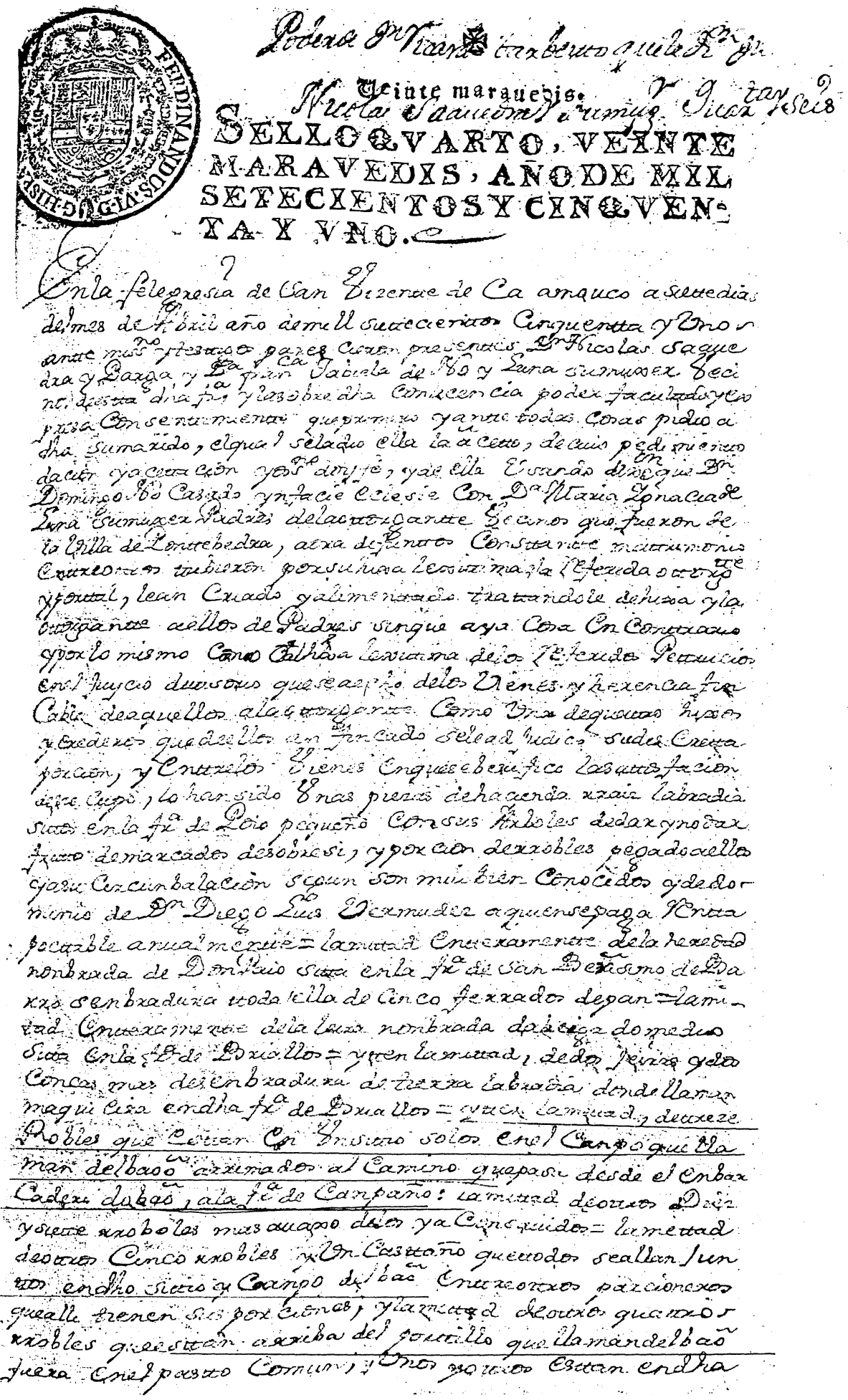




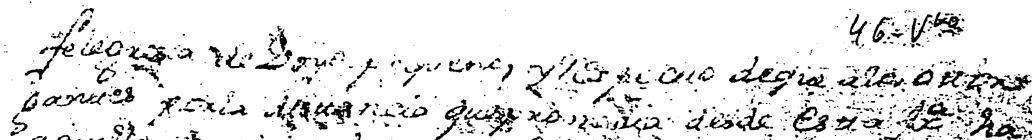

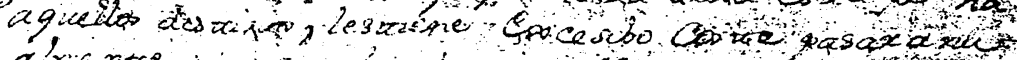

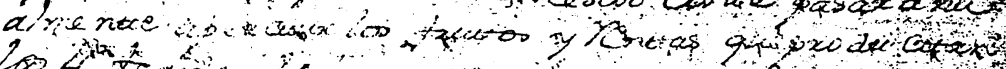

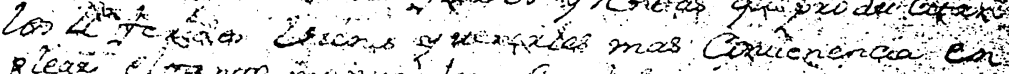

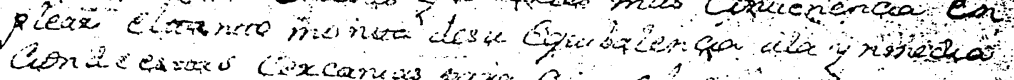

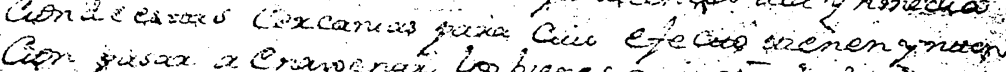

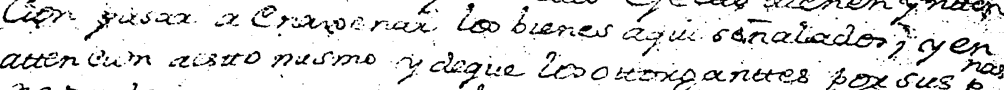

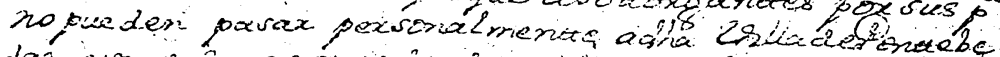

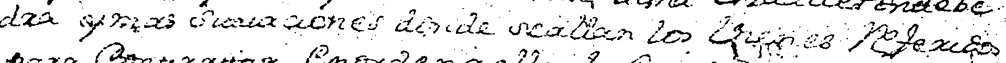

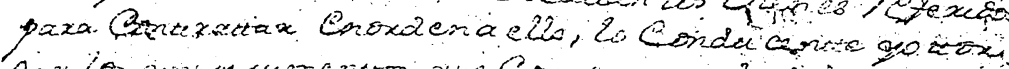

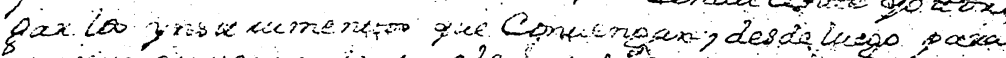

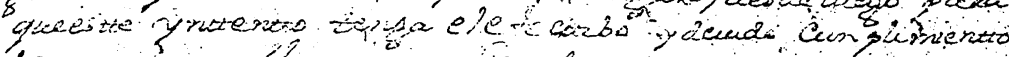

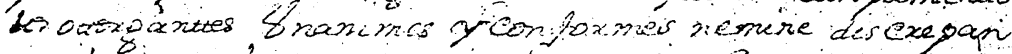

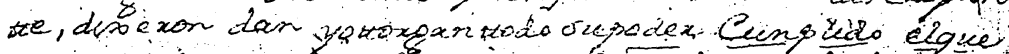

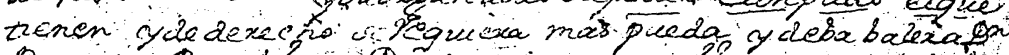

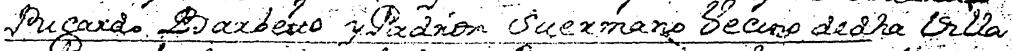

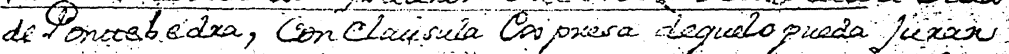

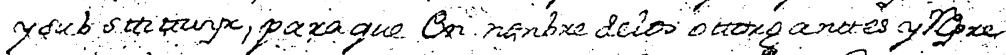

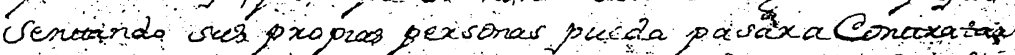

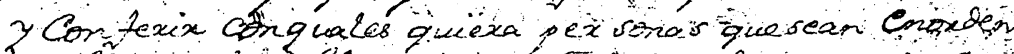

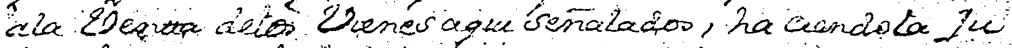

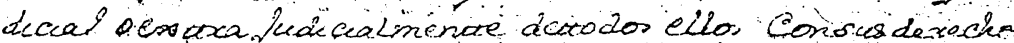

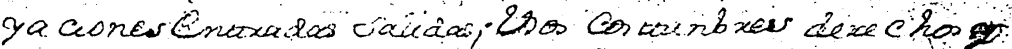

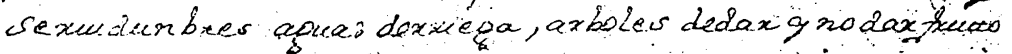

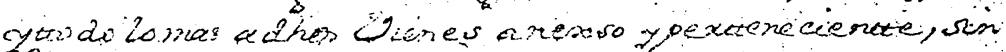

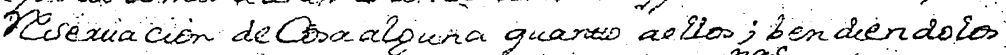

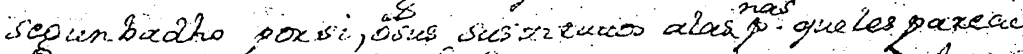

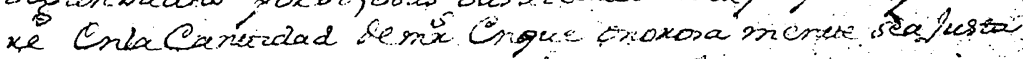

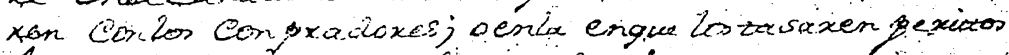

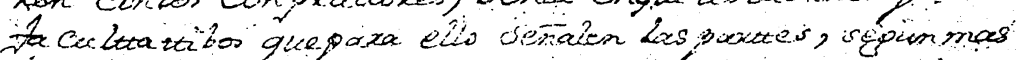

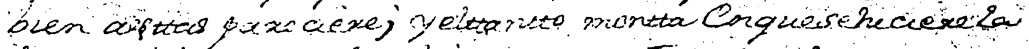

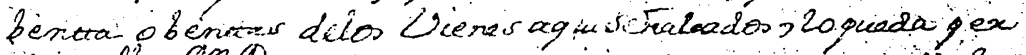

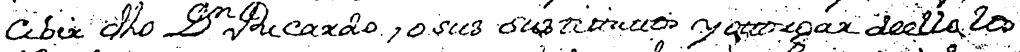

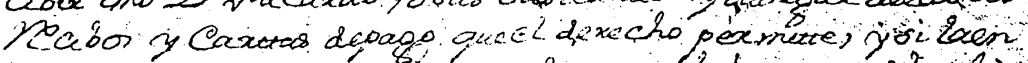

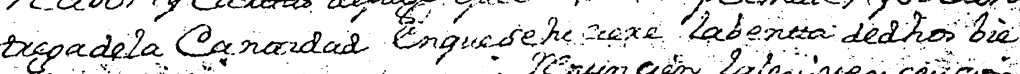

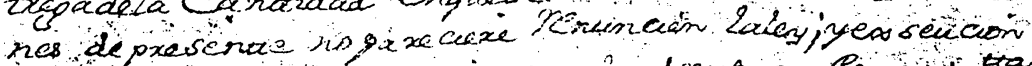

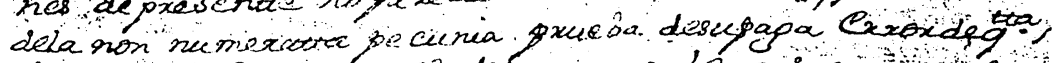

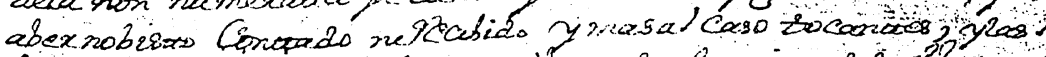

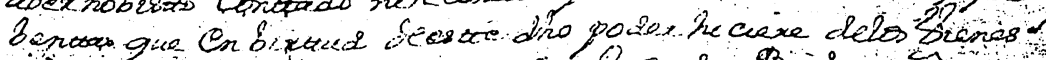

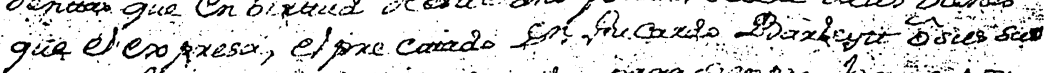

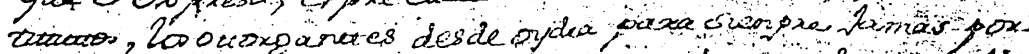

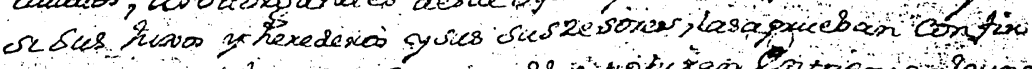

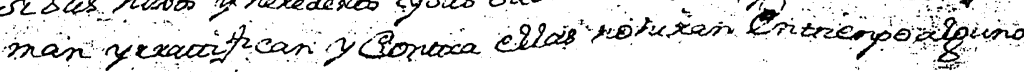




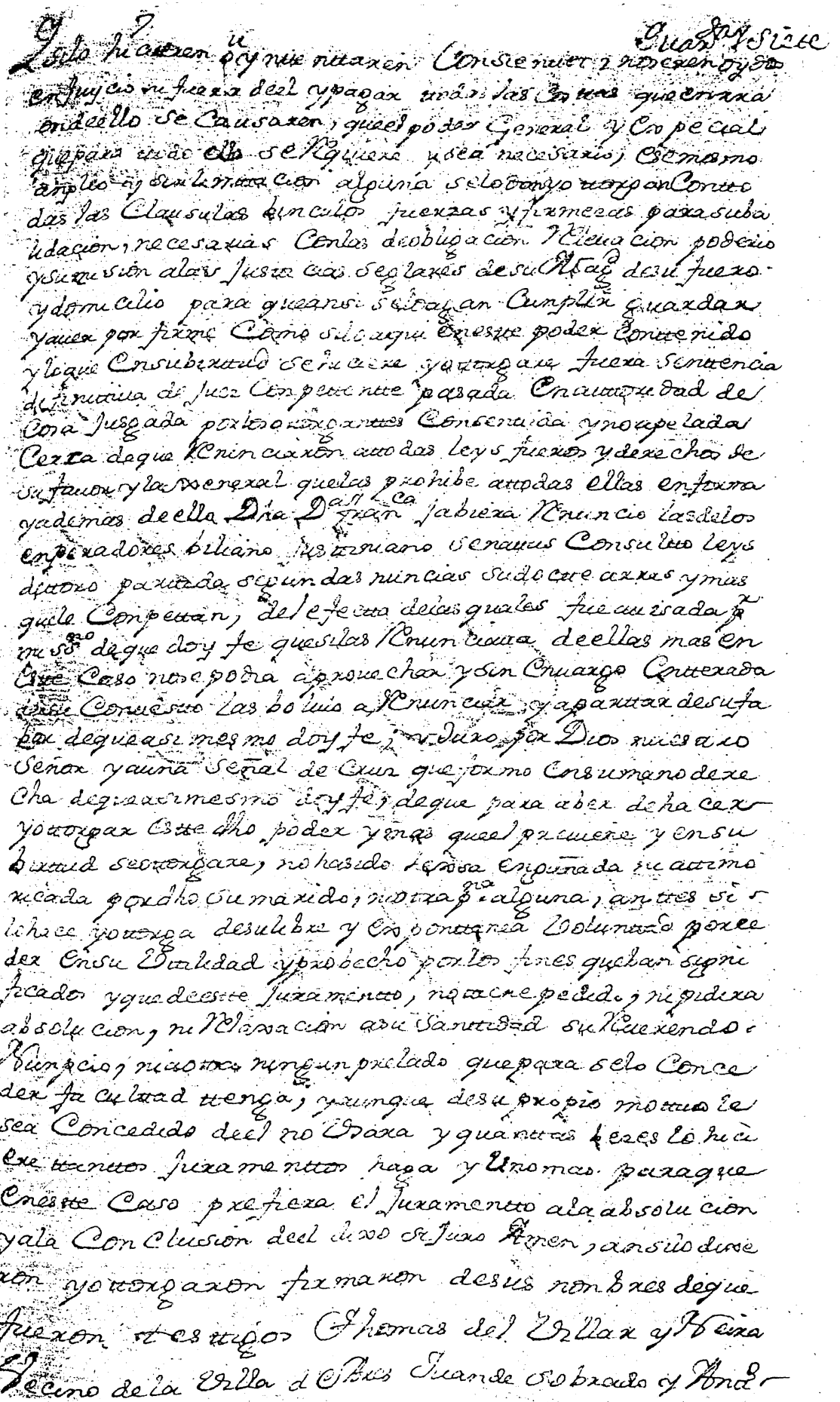




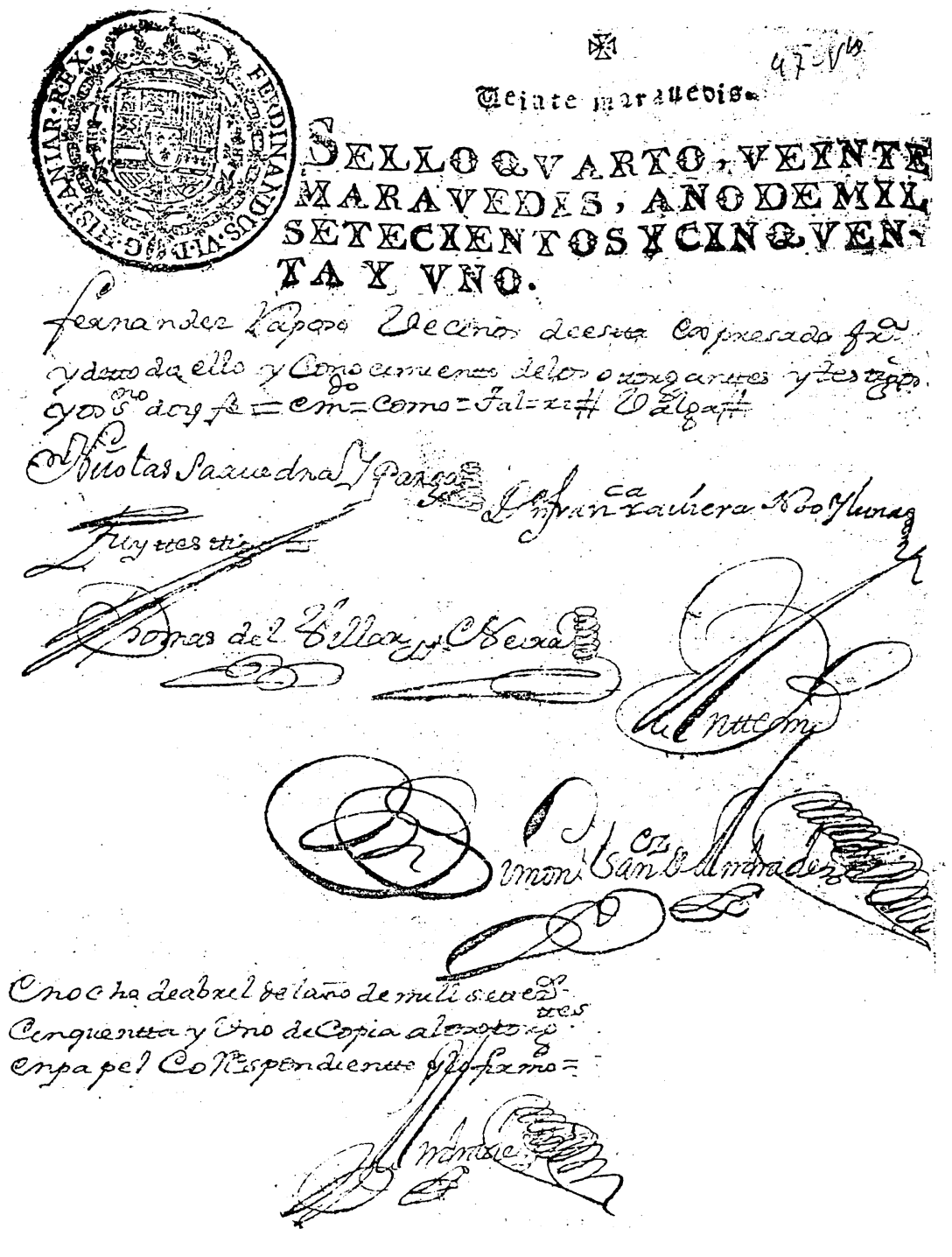

